\title{
Clubfoot: The Treatment Outcome Using Quantitative Assessment of Deformity
}

\author{
AH Rasit, MS Orth, H Azani, MS Orth, PA Zabidah, PhD, A Merikan, MSCP, BA Nur Alyana, BNSs \\ Department of Orthopaedics, Faculty of Medicine \& Health Sciences, Universiti Malaysia Sarawak, Kuching, \\ Malaysia
}

\begin{abstract}
Introduction: The recent trend in management of congenital idiopathic clubfoot tends towards conservative treatment. This study reviews the outcomes of treatment in our practice using the quantitative clubfoot assessment of the deformity (QCAD). Methods: Thirty patients (38 cases of clubfoot) with congenital idiopathic clubfoot treated at Sarawak General Hospital were followed-up for a mean of 3.6 years. The quantitative assessment consists of limb anthropometric measurement and the Pirani deformity severity score. Results: There were 15 boys and 15 girls, with a mean age of 4.4 years (range, $13 \mathrm{~m}-8 \mathrm{y}$ ). Most patients were of the Malay race $(67 \%)$, followed by Chinese $(23 \%)$ and others $(10 \%)$. Eight patients suffered from bilateral congenital idiopathic clubfoot (33\%), 12 were left unilateral (40\%) and 10 were right unilateral $(27 \%)$. Out of the total of 30 patients, 12 were treated conservatively with serial casting and 18 patients were treated surgically after resistance to serial casting at the age of nine months. At follow-up, there were significant differences between the surgical group (2.57 \pm $1.45) ;(0.86 \pm 0.36)$ and conservative group $(0.7 \pm 0.81)$; $(0.34 \pm 0.35)$ respectively $(\mathrm{p}<0.05)$ regarding the mean difference in mid-leg circumference and foot length discrepancy in patients with unilateral clubfoot. There were no significant difference noted between groups with regards to results of the Pirani score, leg length discrepancy and mean difference of mid-foot circumference. Conclusion: There were significant differences in calf atrophy and foot length discrepancy when comparing surgically treated clubfoot patient compared to conservatively treated patients. Conservative treatment of clubfoot is the preferred method of treatment while surgical treatment may be necessary in more resistant cases.
\end{abstract}

Key Words:

Clubfoot, outcome, treatment, quantitative assessment, deformity

\section{INTRODUCTION}

"Club foot", also known as Congenital Talipes Equino Varus (CTEV), is a common congenital deformity of the foot. The estimated birth prevalence of CTEV is 1 per 1,000 live births with approximately $50 \%$ having bilateral clubfeet ${ }^{1}$. In Malaysia, mainly due to the ignorance of parents, clubfoot remains a significant problem and yields an unpredictable outcome due to typical late presentation for treatment ${ }^{2}$. Boo and Ong reported the incidence of clubfoot in Malaysia is 4.5 per 1000 live births ${ }^{3}$. The ratio of male to female is $2.5: 1$ and $24.4 \%$ of affected individuals have a family history of $\mathrm{CTEV}^{4}$.

The aim of treatment is to obtain anatomically and functionally normal feet in all patients ${ }^{5}$. However, this is unrealistic as the deformity of bone, joints, muscles, tendons and ankle, leg and foot ligaments are sometimes too severe to be fully corrected. Conservative treatment of clubfoot is an accepted practice and has been reported to result in good correction ranging in $50 \%-90 \%$ of cases ${ }^{5-7}$. Serial casting tends to prevent further tightening of the contracted structures prior to surgery ${ }^{6,7}$. Treatment should be started early to ensure better outcomes ${ }^{8}$, allowing optimal growth of bone (particularly the talus) and maintenance of joint mobility ${ }^{9}$. Dietz and Cooper published a 30-year follow-up study of patients treated with the Ponseti method indicating that overall patients had comparatively pain-free supple feet ${ }^{10}$.

Some of these deformities recur or become resistant to further conservative treatment. A foot is considered resistant when the deformity shows no evidence of further improvement after 3 months of adequate conservative treatment ${ }^{11}$. Surgery is indicated for a small percentage of cases especially those with resistant clubfoot. Early soft tissue release prior to 36 months of age is well supported by many authors as sufficient time is allowed for the tarsal bones to achieve maximum remodelling ${ }^{6,12-13}$. Some authors have reported between $70-91 \%$ of good to excellent correction in patients who underwent posteromedial release before 6 months of age, and 50\% relapse rate when this procedure was done after 9 months of age ${ }^{12,14}$. Recurrence rates following treatment were reported at approximately $25 \%$ with a range of $10-50 \%{ }^{15,16}$.

The objective of this study was to review the outcome of CTEV treatment at Sarawak General Hospital from 2004 until 2008 using the quantitative clubfoot assessment of the deformity (QCAD). 


\section{MATERIALS AND METHODS}

The study sample consisted of patients who were treated and managed in Sarawak General Hospital from 1 January 2004 until 31 December 2008. All patients were tracked from the outpatient orthopaedics clinic card and inpatient case notes. Inclusion criteria were patients were treated from 1 January 2004 until 31 December 2008. Cases with associated meningomyelocele, arthrogryposis, spina bifida or neurogenic or teratologic conditions were excluded. Patients treated before January 2009 underwent weekly serial casting until achievement of full correction. Cases with resistance to serial casting were treated with soft tissue release without bony procedure between six months to nine months of age except when the patients presented late. For patients who achieved full correction, the affected feet were maintained with an adduction shoe or splint for at least three years of follow-up.

Patients who fulfilled inclusion criteria were examined using the quantitative assessment of the deformity (QCAD) protocol. The assessment consists of anthropometric measurement and the Pirani deformity severity score. Anthropometric measurement includes leg length, mid-leg circumference, foot length and mid-foot circumference. Leg length is measured from the medial knee joint to the medial tip of the medial malleolus. The mid-leg circumference is measured at the midpoint of the leg length. Foot length is measured from the tip of the second toe to the tip of the heel. The midfoot circumference is measured at the midpoint of the foot length. The Pirani deformity score is a simple scoring system based on six clinical signs of contracture ${ }^{17}$. Each is scored according to the following principle: 0 , no abnormality; 0.5, moderate abnormality; 1, severe abnormality. The six signs are separated into two categories; the first three are related to the hind foot (severity of the posterior crease, emptiness of the heel and rigidity of the equinus), and the second three are related to the midfoot (curvature of the lateral border of the foot, severity of the medial crease and position of the lateral part of the head of the talus). Thus, each foot can receive a hindfoot score between 0 and 3, a midfoot score between 0 and 3 and a total score between 0 and 6 .

All data were stored using Microsoft Excel, and statistical analysis was carried out using Statistical Package for the Social Sciences (SPSS) Version 17.0.2 for Windows. Continuous data were expressed as the mean and standard deviation. Differences between the treatment groups with regard to anthropometric measures and Pirani score were analysed using a paired $t$ test. For all statistical analyses, a $\mathrm{p}$ value of $<0.05$ was considered to be significant.

\section{RESULTS}

During the study period, 63 patients out of 100 patients with talipes foot fulfilled the criteria. Only 30 patients were available for this study, because the remaining patients were not contactable due to change of addresses. Out of 30 patients, 15 were boys and 15 were girls. The mean age was 4.4 years. The youngest patient at follow-up was 13 months old and the oldest was 8 years old. The majority of patients were of Malay $(67 \%)$ race, followed by Chinese $(23 \%)$ and others $(10 \%)$. Only eight patients $(33 \%)$ were bilaterally affected, whereas 12 were left unilateral (40\%) and 10 were right unilateral $(27 \%)$.

Twelve patients were treated conservatively with serial casting and 18 patients were treated surgically after resistance to serial casting at the age of nine months. Two out of 12 patients treated conservatively defaulted treatment because of financial problems. These two patients were tracked during the study period and both were referred to Sarawak General Hospital for surgical treatment.

At the time of follow-up study, there were no significant differences in the post-treatment Pirani deformity score (Table I). The anthropometric results of the both conservative and surgical groups are presented in Table II. The mean difference of mid-leg circumference in surgically treated groups and serial casting group was $2.57( \pm 1.45)$ and $0.7( \pm 0.81)$ respectively $(p<0.05)$. The mean difference of foot length discrepancy in surgically treated groups and serial casting group was $0.86( \pm 0.36)$ and $0.34( \pm 0.35)$ respectively $(\mathrm{p}<0.05)$. No significant difference between groups was noted with regard to resultant leg length discrepancy and mean difference of mid-foot circumference.

\section{DISCUSSION}

There was an equal number of males and females in this study and a similar study by Boo and Ong ${ }^{3}$ (Kuala Lumpur, Malaysia). Males outnumber females in the study by Lavy ${ }^{18}$ (Malawi) at a ratio of 1.5 to 1 ; the highest ratio was reported by Alexender ${ }^{19}$ (USA) with ratio of 2.9 to 1 . In studies by Wallander et al. ${ }^{20}$ (Sweden) and Carey et al. ${ }^{21}$ (Western Australia), the ratio of male to female was 2.4 and 2.0 to 1 respectively.

Malay was the predominant race in our study, similar to the report by Boo and $\mathrm{Ong}^{3}$. This finding may be equally reflective of the racial distribution of the city of Kuching (location of the present study) in our study and Kuala Lumpur in Boo study, as Malay is the majority race in both of these Malaysian cities. Chung et al ${ }^{22}$ report racial variations in predisposition to talipes with a higher prevalence in Hawaiians than in Caucasians (6.8 compared to 1.1 per 1000). In another study (Byron et al.) ${ }^{23}$, the incidence of CTEV was more common in maternal aboriginal compared to other races in South Australia.

In the present study, the majority of the cases were unilateral $(67 \%)$, similar to results reported by Byron ${ }^{25}$ and Wallander ${ }^{22}$ 
Table I: Comparison of mean Pirani severity score between surgically and conservatively treated patients

\begin{tabular}{|lccc|}
\hline & Surgery $(\boldsymbol{n}=24)$ & Conservative $(n=15)$ & $P$ Value \\
\hline Pirani score $($ mean +/- SD) & $0.42 \pm 0.56$ & $0.6 \pm 1.28$ & $P>0.05(p=0.6)$ \\
\hline
\end{tabular}

† $P$ values were calculated with paired $t$ tests.

Table II: Comparison of Anthropometrics measurement between surgically and conservatively treated patient in unilateral affected patients

\begin{tabular}{|lccc|}
\hline & Surgery $(\mathbf{n}=14)$ & Conservative $(\mathbf{n}=\mathbf{8})$ & $\mathbf{P}$ Value† \\
\hline Difference of leg length (Mean +/- SD) & $0.071 \pm 0.18$ & $0228 \pm 0.41$ & $p>0.05(p=0.43)$ \\
Difference of Mid leg Circumference (Mean +/- SD) & $2.57 \pm 1.45$ & $0.7 \pm 0.81$ & $P<0.05(P=0.0016)$ \\
Difference of foot length (Mean +/- SD) & $0.86 \pm 0.36$ & $0.34 \pm 0.35$ & $p<0.05(p=0.01)$ \\
Difference of mid foot circumference (Mean +/- SD) & $0.52 \pm 1.30$ & $0.24 \pm 0.25$ & $p>0.05(p=0.48)$ \\
\hline
\end{tabular}

Difference between normal leg and abnormal leg.

$\dagger \mathrm{P}$ values were calculated with paired $\mathrm{t}$ tests.

in which $55 \%$ and $54 \%$ of cases were unilateral respectively. Other studies reported marginally more bilateral than unilateral ${ }^{3,20}$. The left foot was more commonly affected in unilateral cases in our study and also in the study by Boo and Ong ${ }^{3}$. In contrast, Byron ${ }^{25}$ and Wallander ${ }^{22}$ reported right unilateral as more common.

All surgically treated patients in the present study were initially treated with serial casting until the age of nine months. Resistant patients were treated surgically with open soft tissue release without bony procedure. There was no significant different between the conservatively treated and surgically treated patients in term of final Pirani score; however, there was a significant difference noted in the degree of calf atrophy in the surgically treated patient. This finding may be due to the fact that all surgically treated patients were resistant to serial casting.

\section{CONCLUSION}

There were significant differences in calf atrophy and foot length discrepancy in surgically treated clubfoot patients compared to conservatively treated patients. Conservative treatment of clubfoot is the preferred method of treatment although surgical treatment may be necessary in resistant cases. 


\section{REFERENCES}

1. Dobbs MB, R. J. Factors predictive of outcome after use of ponsenti method for treatment of idopathic clubfeet. J Bone Joint Surg Am 2004; 86 (1): 22-7.

2. Nordin S, A. M. Controversies in Congenital Clubfoot: Literature review. Malays J Med Sci 2002; 9(1): 34-40.

3. Boo NY, O. L. Congenital Talipes in Malaysian Neonates: Incidence, pattern and associated factors. Singapore Med J 1990; 31 : $539-42$.

4. Lochmiller C, J. D. Genetic Epidemiology study of idopathic talipes equinovarus. Am J Med Genet, 1998; 79: 90-96.

5. Kite JH. The Clubfoot. New York: New York Grune and Stratton;1964

6. Magone JB, Torch MA, Clark RN, \& Ken JR. Comparative review of surgical treatment of the idoipathic clubfoot by 3 different procedures at Columbus Children's Hospital. J Pediatr Orthop 1997; 9(1): 49-58.

7. Ponseti IV. Current Concepts: Common errors in the treatment of congenital clubfoot. Int Orthop 1997; 21: 137-41.

8. Ikeda K. Conservative Treatment of Idiopathic Clubfoot. J Pediatr Orthop. 1992; 12: 217-23.

9. Lehman WB. The Clubfoot. Philadelphia: Lippincott. 1980

10. Stromqvist B, Johnson, R., Johnson, K., \& Sunden, G. Early Intensive Treatment of Clubfoot. 75 feet Followed for 6-11 Years. Acta Orthop Scan 1992; 63 (2): 183-8.

11. McKay DW. New Concepts of an Approach to Clubfoot Treatment Section 1: Correlation of the Clubfoot. J Pediatr Orthop 1983; 3: $10-21$.

12. Cooper DM, \& Dietz, FR. Treatment of idiopathic clubfoot. A thirty-year follow-up note. J Bone Joint Surg Am 1995; 77 (10): 1477-89.

13. Porter RW. Congenital Talipes Equinovarus Mini Symposium: The Foot in Childhood. Curr Orthop 1992; 6: 77-80.

14. Depuy J, \& Drennan JC. Correction of Idiopathic: A Comparison of Result of Early Versus Delayed Posteromedial Relaese. $J$ Pediatr. Orthop 1989; 9: 44-8.

15. Main BJ, \& Crider, RJ. An Analysis of Residual Deformity in Clubfeet Submitted to Early Operation. J Bone Joint Surg 1978; 60(13): 536-43.

16. Thompson GH, Richardson AB, \& Weistin GW. Surgical Management and Resistant Congenital Talipes Equinovarus Deformities. J Bone Joint Surg Am 1982; 64 (5): 652-65.

17. Parot S, Milgrom C, \& Bentley G. The History of Treatment of Congenital Clubfoot at the Royal Liverpool Children's Hospital: Improvement of Results by Early Extensive Posteromedial relaese. J Pediatr Orthop 1984; 4: 331-8.

18. Haft GF, Walker, CG, \& Crawford H A. Early Clubfoot recurrence after use of the Ponseti method in a New Zealand population. J Bone Joint Surg Am 2007; 86(3): 487-93.

19. Dobbs MB, Morcuende, JA, Corley CL, \& Ponseti, I. V. Late recurrence of clubfoot deformity: a 45-year follow up. Clin Orthop Relat Res. 2003; 411: 188-92.

20. Pirani S, Outerbridge HK, Sawatzky B, Stothers K. A reliable method of clinically evaluating a virgin clubfoot evaluation. 21 st SICOT Congress 1999.

21. Lavy CBD, Mannion SJ, Mkandawire NC, Tindall A, Steinlechner C, Chimangeni S, Chipofya E. Club foot treatment in Malawipublic health approach. Disabil Rehabil 2007 ; 29: 857-62.

22. Alexander Hersh. The role of surgery in the treatment of club feet. J Bone Joint Surg Am 1967; 49: 1684-96.

23. Wallander H, Hovelius L and Michaelsson K. Incidence of congenital clubfoot in Sweden. Acta Orthop 2006; 77(6): 847-52.

24. Carey M, Mylvaganam A, Rouse I and Bower C. Risk factors for isolated talipes equinovarus in Western Australia 1980-1994. Paediatr Perinat Epidemiol 2005; 19: 238-45.

25. Chung C, Nemechek R, Larsen I, Ching G. Genetic and epidemiological studies of clubfoot in Hawaii. Human Hered 1969; 19: 321-42.

26. Byron-Scott R, Sharpe P, Hasler C, Cundy P, Hirte C, Chan A, et al. A south australian Population-based study of congenital talipes equinovarus. Paediatr Perinat Epidemiol. 2005; 19: 227-37. 